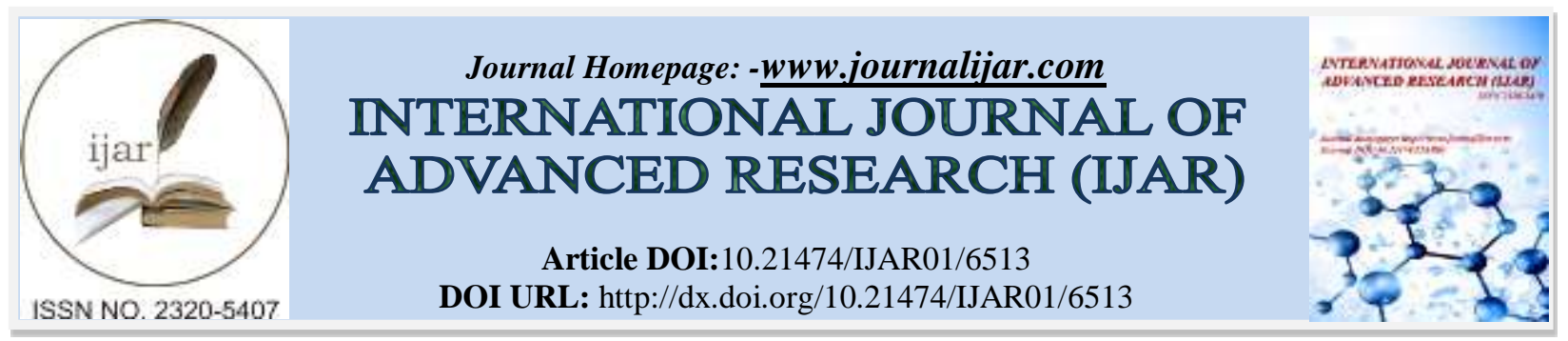

RESEARCH ARTICLE

\title{
EFFECT OF HYPERGLYCEMIA ON OUTCOME OF ACUTE EXACERBATION OF CHRONIC OBSTRUCTIVE PULMONARY DISEASE.
}

\section{Dr. Kamlesh Kumar Gupta ${ }^{1}$, Dr. Vinod Kumar ${ }^{2}$, Dr. Shyam chand Chaudhary ${ }^{3}$, Dr. Arvind Mishra ${ }^{4}$, Dr.} Munna Lal Patel ${ }^{5}$ and Dr. Bidyut Roy ${ }^{6}$.

1. Associate professor, Department of medicine, KGMU.

2. Junior resident III, Department of medicine, KGMU.

3. Professor junior grade, Department of medicine, KGMU.

4. Professor, Department of medicine, KGMU.

5. Associate professor, Department of medicine, KGMU.

6. Senior resident, Department of medicine, KGMU.

\section{Manuscript Info}

Abstract

Manuscript History

Received: 12 December 2017

Final Accepted: 14 January 2018

Published: February 2018

Copy Right, IJAR, 2018,. All rights reserved.

\section{Introduction:-}

COPD is a growing cause of morbidity and mortality worldwide, and will be the third leading cause of death by 2020. The Global Initiative for Chronic Obstructive Lung Disease (GOLD) recently defined COPD as "Chronic Obstructive Pulmonary Disease (COPD) is a common, preventable and treatable disease that is characterized by persistent respiratory symptoms and airflow limitation that is due to airway and/or alveolar abnormalities usually caused by significant exposure to noxious particles or gases". ${ }^{[1]}$ Hyperglycaemia is of interest as it is associated with poor outcomes from acute hospital admission for other conditions. Hyperglycemia associated with critical illness (also called stress hyperglycemia or stress diabetes) is a consequence of many factors, including increased cortisol, catecholamines, glucagon, growth hormone, gluconeogenesis, and glycogenolysis. Insulin resistance may also be a contributing factor. Acute hyperglycaemia is associated with poor outcomes from a wide range of acute illnesses including myocardial infarction, ${ }^{[2]}$ stroke, ${ }^{[3]}$ trauma and pneumonia ${ }^{[4]}$. Hyperglycaemia is thus associated with a poor outcome from a wide range of acute illnesses. However, the relationship between blood glucose levels and clinical outcomes in AECOPD has not been fully studied. The present study was undertaken to determine the relationship between blood glucose concentrations, HBA1c levels and clinical outcomes in patients of AECOPD.

\section{Materials and Method: -}

Study Design: -

Prospective study

\section{Study Population:-}

The study was done over a period of one year from September 2016 to August 2017 in King George's Medical University, Lucknow. The study group comprised of COPD patients aged 40-90 years, who gave consent to be a part of the study, diagnosed previously by history and examination and admitted as acute exacerbation of COPD and 
severity was determined according to GOLD classification criteria. On the basis of history, acute exacerbation was diagnosed by the following criteria:

1. Recent rapid worsening of dyspnea

2. Increase in Sputum Purulence

3. Increase in Sputum volume

Patients who did not give consent, gave history of bronchial asthma, interstitial lung disease, pulmonary tuberculosis / bronchiectasis, concomitant cardiac disease, renal disease, liver disease or malignancy were excluded. All patients of AECOPD who fulfilled the inclusion criteria, admitted in Department of Medicine, KGMU, Lucknow, were enrolled for the study. Random blood sugar level was estimated by GOD-POD method (glucose oxidase peroxidase, kits by Erba) method at the time of admission. A $2 \mathrm{~mL}$ peripheral blood sample was taken for Glycosylated hemoglobin (HBA1C). The length of hospital stay of each patient was recorded in days. If a patient expired during the course of the hospital stay, then it was recorded as an outcome. A composite adverse outcome was defined as, death or length of stay longer than the median length of stay for analysis. Data was entered in structured tables for comparison where the study population was divided into groups or quartiles according to different age groups, blood glucose levels and HBA1C.

\section{Methods:-}

AECOPD Patients were enrolled and their informed consent were taken. A detailed clinical history and physical examination was carried out for every subject. In the clinical history duration of COPD with history of exacerbation and treatment were inquired. All patients were subjected to a CAT questionnaire (COPD Assessment Test) and MMRC (Modified Medical Research council) dyspnea scale, on the basis of which disease severity was calculated. History of presence of risk factor like smoking, hypertension, dyslipidemia, diabetes mellitus, and presence of any other chronic disease was inquired. Following Biochemical investigations were also carried out - haemogram, renal function test, liver function test, PT-INR, HBA1C, blood sugar (fasting and post prandial), CXR-PA view, fasting lipid profile, sputum routine microscopy, 2D Echo examination, Pulmonary function test.

The statistical analysis was done using SPSS (Statistical Package for Social Sciences) Version 15.0 statistical Analysis Software. The values were represented in Number (\%) and Mean \pm SD.

\section{Results:-}

A total of 107 COPD patients were enrolled in the study of which 6 patients died. So that only 101 patient underwent follow up. Demographic details of 101 patients enrolled in the study are as under:

Table 1:- Age wise Distribution of Study Population

\begin{tabular}{|c|c|c|c|}
\hline SN & Age Group & No. of patients & Percentage \\
\hline $1-$ & $41-55$ years & 7 & 6.93 \\
\hline $2-$ & $56-65$ years & 32 & 31.68 \\
\hline $3-$ & $66-75$ years & 47 & 46.53 \\
\hline $4-$ & $76-85$ years & 11 & 10.89 \\
\hline $5-$ & $>85$ years & 4 & 3.96 \\
\hline & & 101 & 100.00 \\
\hline
\end{tabular}

Min-Max (Median): 48-88 (69.00); Mean $\pm S D: 67.92 \pm 8.82$

Out of 101 COPD patients enrolled in the study, $66(65.35 \%)$ had random blood sugar levels $\leq 200 \mathrm{mg} / \mathrm{dl}$ were classified as Group I and rest 35 (34.65\%) patients having random blood sugar levels $>200 \mathrm{mg} / \mathrm{dl}$ were classified as Group II (Hyperglycemic). Sub categorization was done on the basis of RBS and is listed as under:

Table 2:- Group wise Distribution of Study Population

\begin{tabular}{|c|l|c|c|c|}
\hline SN & Group/ Subgroup & Description & No. of patients & Percentage \\
\hline $1-$ & Group I & RBS $\leq 200$ & 66 & 65.35 \\
\hline & Subgroup Ia & $<140 \mathrm{mg} / \mathrm{dl}$ & 31 & 30.69 \\
\hline
\end{tabular}




\begin{tabular}{|c|l|c|c|c|}
\hline & Subgroup Ib & $140-170 \mathrm{mg} / \mathrm{dl}$ & 19 & 18.81 \\
\hline & Subgroup Ic & $171-200 \mathrm{mg} / \mathrm{dl}$ & 16 & 15.84 \\
\hline $2-$ & Group II & RBS >200 & 35 & 34.65 \\
\hline
\end{tabular}

Our study showed that the duration of hospital stay among patients of Group II (9.63 \pm 2.04 days) was found to be significantly higher as compared to Group I (6.89 \pm 2.08 days). A subsequent increase in duration of hospital stay was observed among Subgroup Ia (6.00 \pm 1.93 days), Subgroup Ib (6.89 \pm 2.08 days), Subgroup Ic ( $8.63 \pm 1.09$ days) and Group II (9.63 \pm 2.04 days) was observed. Subgroup analysis was done using the ANOVA test (Analysis of Variance) and the results were found to be statistically significant with $\mathrm{p}$ value $<0.001$. Table- 3 shows intergroup comparison of the duration of illness and hospital stay as follows-

Table 3:- Intergroup Comparison of Duration of Illness and Hospital Stay among patients with different levels of blood sugar

\begin{tabular}{|c|c|c|c|c|c|c|c|c|c|c|}
\hline & \multicolumn{2}{|c|}{$\begin{array}{c}\text { Subgroup Ia } \\
(\mathbf{n}=\mathbf{3 1})\end{array}$} & \multicolumn{2}{|c|}{$\begin{array}{c}\text { Subgroup Ib } \\
(n=19)\end{array}$} & \multicolumn{2}{|c|}{$\begin{array}{l}\text { Subgroup Ic } \\
\text { (16) }\end{array}$} & \multicolumn{2}{|c|}{$\begin{array}{c}\text { Group II } \\
(\mathbf{n}=35)\end{array}$} & \multicolumn{2}{|c|}{ ANOVA } \\
\hline & Mn & SD & Mn & SD & Mn & SD & Mn & SD & $\mathbf{F}$ & $\mathbf{P}$ \\
\hline \multirow{2}{*}{$\begin{array}{l}\text { Duration of } \\
\text { hospital stay } \\
\text { (Days) }\end{array}$} & 6.00 & 1.93 & 6.89 & 2.08 & 8.63 & 1.09 & 9.63 & 2.04 & 22.537 & $<0.001$ \\
\hline & \multicolumn{6}{|c|}{ GROUP I $n=66$} & \multicolumn{4}{|c|}{ GROUP II n=35 } \\
\hline $\begin{array}{lr}\begin{array}{l}\text { Duration of } \\
\text { hospital stay } \\
\text { (days) }\end{array} \\
\end{array}$ & \multicolumn{2}{|c|}{ Mean 6.89} & \multicolumn{2}{|c|}{ SD 2.08} & & & \multicolumn{2}{|c|}{ Mean 9.63} & \multicolumn{2}{|c|}{ SD 2.04} \\
\hline
\end{tabular}

In our study it was also observed that majority of patients of Group I (80.30\%) had HbA1c levels $\leq 6 \%$ while majority of patients of Group II $(65.71 \%)$ had HbA1c levels $>6 \%$.

Difference in duration of hospital stay of patients of Group I, having HbAlc $\leq 6$ (6.28 \pm 1.69 days) and HbA1c $>6$ $(9.38 \pm 1.61$ days) was found to be statistically highly significant $(t=5.978 ; \mathrm{p}<0.001)$.

Difference in duration of hospital stay of patients of Group II, having HbAlc $\leq 6$ ( $8.92 \pm 2.35$ days) and HbA1c $>6$ $(10.00 \pm 1.81$ days $)$ was not found to be statistically significant $(t=1.516 ; p=0.139)$. Table- 4 shows the association of HBA1c levels with the duration of hospital stay as follows-

Table 4:- Association of HbA1c and duration of hospital stay

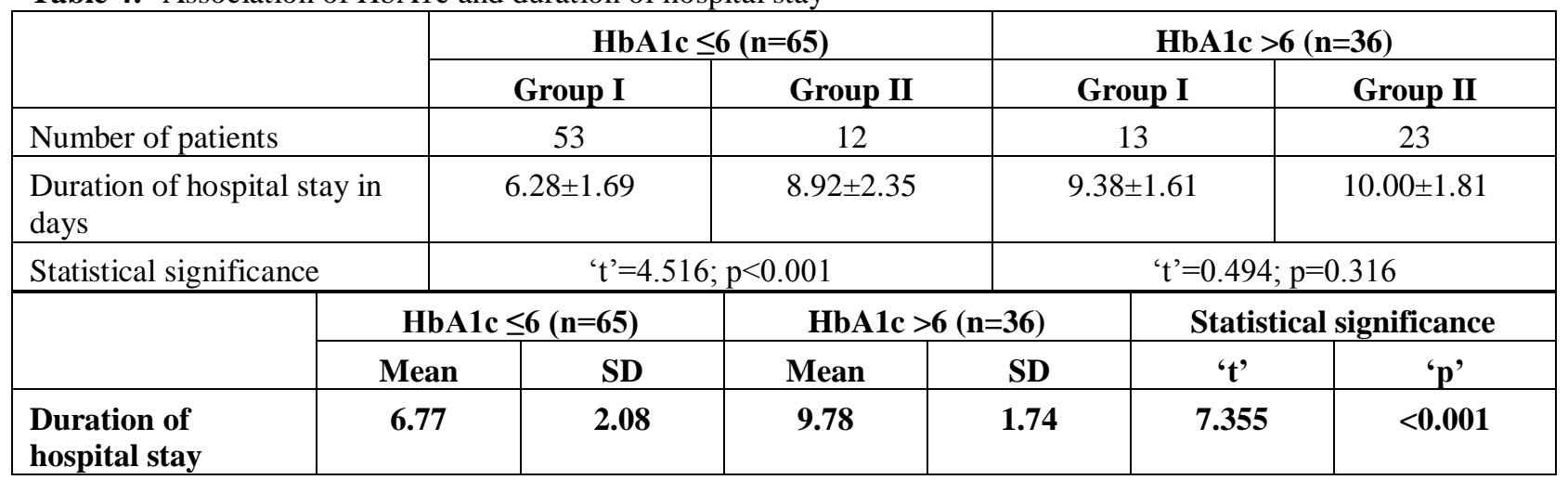

Mean duration of hospital stay of patients having HbAlc $>6(9.78 \pm 1.74$ days $)$ was found to be higher than that having HbAlc $\leq 6$ (6.77 \pm 2.08 days). Difference in hospital stay of patients with HbAlc levels $\leq 6$ and HbAlc $>6$ was found to be statistically significant. 
In our study of the 107 patients enrolled, 6 deaths were reported. All 6 patients belonged to GOLD stage D as indicated by their past medical records and past history. Amongst these 6 patients, 5 patient's RBS at admission was more than $200 \mathrm{mg} / \mathrm{dl}$. The percentage of mortality increased as the random blood glucose level increased. All deaths reported were in patients over 66 years of age.

\section{Discussion:-}

Patients enrolled in our study ranged between $48 \& 88$ years, with the median age being 69 years and mean age of patients was $67.92 \pm 8.82$ years (Table 1). Only 7 (6.93\%) patients were aged 41-55 years and 32 (31.68\%) 56-65 years. Most common age group was 66-75 years (46.53). Out of the 101 COPD patients enrolled in the study, $66(65.35 \%)$ had random blood sugar levels $\leq 200 \mathrm{mg} / \mathrm{dl}$ were classified as Group I and the remaining $35(34.65 \%)$ patients having random blood sugar levels $>200 \mathrm{mg} / \mathrm{dl}$ were classified as Group II (Hyperglycemic). Group I was further divided in three subgroups - 31 (30.69\%) patients had random blood sugar levels <140 mg/dl were classified as Subgroup Ia, 19 (18.81\%) patients having random blood sugar levels 140-170 mg/dl were classified as Subgroup $\mathrm{Ib}$ and 16 patients having random blood sugar levels $171-200 \mathrm{mg} / \mathrm{dl}$ were classified as Subgroup Ic. Duration of hospital stay among patients of Group II (9.63 \pm 2.04 days) was found to be significantly higher as compared to Group I (6.89 \pm 2.08 days). A subsequent increase in duration of hospital stay was observed among Subgroup Ia (6.00 \pm 1.93 days), Subgroup Ib (6.89 \pm 2.08 days), Subgroup Ic ( $8.63 \pm 1.09$ days) and Group II (9.63 \pm 2.04 days) was observed. This association was found to be statistically significant $(\mathrm{p}<0.001)$. Majority of patients of Group I $(80.30 \%)$ had HbA1c levels $\leq 6 \%$ while majority of patients of Group II $(65.71 \%)$ had HbA1c levels $>6 \%$. Difference in HbA1c levels of Group I and Group II patients was found to be statistically significant. Mean duration of hospital stay of patients having HbAlc $>6(9.78 \pm 1.74$ days $)$ was found to be higher than that having HbA1c $\leq 6$ (6.77 \pm 2.08 days). Difference in hospital stay of patients with HbA1c levels $\leq 6$ and HbA1c $>6$ was found to be statistically significant. No association was found between HbA1c levels and the COPD GOLD stage. Among the 107 patients enrolled in our study a total of 6 deaths were recorded. All 6 patients belonged to GOLD stage D as indicated by their past medical records and past history. Of these 6 patients, 5 patient's RBS at admission was more than $200 \mathrm{mg} / \mathrm{dl}$. It was observed in our study that the percentage of mortality increased as the random blood glucose level increased.

In the study done by Pramila et al; 2016, the hyperglycemia was assumed as random blood glucose levels $>140$ $\mathrm{mg} / \mathrm{dl}$. Out of 100 patients $35 \%(\mathrm{n}=35)$ were normoglycemic and $65 \%(\mathrm{n}=65)$ were hyperglycemic ${ }^{[5]}$. Statistically significant relation was found between the quartiles of RBS $\leq 140 \mathrm{mg} / \mathrm{dl}$ with $171-200 \mathrm{mg} / \mathrm{dl} \& \geq 201 \mathrm{mg} / \mathrm{dl} \mathrm{with} \mathrm{p}$ value 0.01 . This study inferred that RBS more than $170 \mathrm{mg} / \mathrm{dl}$ is detrimental in AECOPD patients. Archer et al; 2011, in his prospective, non-randomized, single arm study of intensive glycemic control in AECOPD patients demonstrated that intensive glucose control can be achieved within the acute medical ward with a similar safety and efficacy to that achieved in patients admitted to an intensive care unit, and the control of blood sugar could potentially have some benefit in AECOPD patients ${ }^{[6]}$. Burt, et al; 2014, reported that the length of hospital stay is increased by $10 \%$ (21hours) for each $18 \mathrm{mg} / \mathrm{dl}$ increase in mean glucose $(\mathrm{P}=0.01) 10$. In this study the blood glucose levels of 47 patients were monitored continuously using a device to measure interstitial glucose levels to determine the pattern of hyperglycemia in patients receiving prednisolone for AECOPD. Higher mean daily glucose levels were positively associated with longer hospital stays; this relationship with length of stay was not significant for other markers of disease severity ${ }^{[7]}$. Naghamjafar md et al; 2015, Hyperglycemia has been associated with increased morbidity, increased mortality, and longer lengths of stay, and more hospital costs in patients with both medical and surgical conditions ${ }^{[8]}$. In a study by Deepali J. Kamdar, Dharmeshkumar Patel; 2017, A statistically significant relationship was obtained between male gender, smoking history (odd ratio of 1.5), number of pack years $(\mathrm{p}=$ 0.029 ), history of prior admission (odds ratio of 2$)$, longer duration of illness $(\mathrm{p}=0.045)$, elevated blood sugar levels $(\mathrm{p}=0.035)^{[9]}$.

Acute exacerbation of COPD, much like any other critical illness, is associated with hyperglycemia due to the stress related hormonal response to acute illness and possibly some of the medications routinely used in the treatment of AECOPD. While several studies have previously suggested that hyperglycemia has adverse outcomes in patients with AECOPD, but the pathophysiology underlying these outcomes is yet to be determined. Further research is needed on the various outcomes in AECOPD in patients with deranged blood sugar, using a larger sample size and taking into consideration a design that will provide more insight into the pathophysiology. In addition, a study on predefined targets of glycemic control and outcomes is needed ${ }^{[156]}$. 


\section{Conclusion:-}

Our study corroborates the evidence gathered from studies by previous authors and implicates hyperglycemia as a potentially harmful and correctable abnormality in critically ill patients and support ongoing consideration of hyperglycemia as a therapeutic target to improve outcomes in hospitalized patients of AECOPD. The finding that the magnitude of mortality risk from hyperglycemia depends on the underlying disease suggests that the degree of benefit from glucose-lowering may differ among patients with certain conditions. The results gathered from our study suggest that strict control of blood sugar in the prehospitalisation period as well as during hospital stay results in better outcomes such as shortened duration of hospital stay; decreased mortality and morbidity.

\section{Limitations:-}

This was a single centre study and majority of the patients were in GOLD stage C or D. The study was carried out on a limited patient population, so we recommend a multicentre study with a larger sample size so that the true relation between hyperglycemia, HbA1C and outcome of Acute Exacerbation of COPD is established.

\section{References:-}

1. Global Initiative for Chronic Obstructive Lung Disease (GOLD) Global strategy for the diagnosis, management, and prevention of COPD (revised 2017).

2. Capes S, Hunt D, Malmberg K, Pathak P, Gerstein H. Stress Hyperglycemia and Prognosis of Stroke in Nondiabetic and Diabetic Patients: A Systematic Overview. Stroke. 2001;32(10):2426-2432

3. Capes S, Hunt D, Malmberg K, Pathak P, Gerstein H. Stress Hyperglycemia and Prognosis of Stroke in Nondiabetic and Diabetic Patients: A Systematic Overview. Stroke. 2001;32(10):2426-2432

4. Umpierrez G, Isaacs S, Bazargan N, You X, Thaler L, Kitabchi A. Hyperglycemia: An Independent Marker of In-Hospital Mortality in Patients with Undiagnosed Diabetes. The Journal of Clinical Endocrinology \& Metabolism. 2002;87(3):978-982

5. Devi P,Goornavar SM,Kanumuri R. Correlation of blood glucose levels on the outcome of patients with acute exacerbation of chronic obstructive pulmonary disease. Indian Journal Of Applied Medical Research. 2016 March;5(2) :103-112.

6. R Castellanos M, Szerszen A, Saifan C, Zigelboym I, Khoueiry G, Abi Rafeh N. Fasting hyperglycemia upon hospital admission is associated with higher pneumonia complication rates among the elderly. International Archives of Medicine. 2010

7. The association between blood glucose levels and hospital outcomes in patients admitted with acute exacerbations of chronic obstructive pulmonary disease. The Southwest Respiratory and Critical Care Chronicles. 2014;2(7).

8. Nugent $\mathrm{K}$, Islam E, Limsuwat $\mathrm{C}$, Nantsupawat T, Berdine G. The association between glucose levels and hospital outcomes in patients with acute exacerbations of chronic obstructive pulmonary disease. Annals of Thoracic Medicine. 2015;10(2):94

9. Kamdar D, Patel D. A prospective study of the predictors of mortality in acute exacerbation of COPD: an Indian perspective. International Journal of Advances in Medicine. 2017;4(2):362. 